\title{
The Electorate's Partisan Evaluation: Evidence of a Continuing Democratic Edge
}

\author{
John G. Geer
}

\begin{abstract}
Scholars have devoted a good deal of attention to studying changes in how the public evaluates the Democratic and Republican parties. However, there have been few attempts to examine the underlying components of the changes in these overall evaluations of the parties in detail. By recoding the Center for Political Studies' open-ended likes/dislikes questions for parties, this paper maps change in the underlying partisan evaluations of the electorate since 1952. The results suggest that the Democrats have remained the favored party, despite some gains by the GOP in recent years. Of the eight issues studied, the Republicans have made significant inroads only on the economic front. The findings also highlight the obstacles that face the Republican's effort to gain majority status, suggesting why it has remained the minority party for over 50 years, and why it is likely to remain in that position in the near future.
\end{abstract}

With the defeat of Michael Dukakis in 1988, the Democrats have lost five of the last six presidential elections, winning ten or fewer states in four of those contests. The Democrats have also lost a sizable share of self-identified partisans in recent years. In 1980, for instance, the Democrats held a twenty percentage point lead over the Republicans. By 1988, that lead had shrunk to about six percentage points. In addition, there are indications of a pro-Republican tide among the youth of the nation, suggesting that further gains by the GOP may be on the horizon. Work by Cavanagh and Sundquist (1985), Norpoth (1987), Norpoth and Kagay (1989), Petrocik (1987), Shanks and Miller (1989), and Wattenberg (1987 and 1990) all lend support to the claim that the fortunes of the Democratic party have been waning. 
While the GOP has made gains in the 1980s, this trend need not continue. The fortunes of the parties have had peaks and valleys over the last 50 years. In 1964, for instance, the GOP appeared to be retreating on nearly all fronts. Yet by 1968 , the GOP had won the White House and had also made sizable inroads into the Democrat's edge in self-identified partisans. Such shifts suggest that we should be cautious when interpreting the recent changes in the public's attitudes toward the parties. Caution may be particularly appropriate in this case, given that the Democrats retain a plurality of self-identified partisans, control both houses of Congress, and hold a majority of governorships and legislatures in the fifty states.

To detect the depth of the GOP's gains and thereby develop a better sense of the relative standing of the two parties, I examine changes in the public's evaluations of Democratic and Republican parties since 1952. This examination does not include the public's assessment of presidential contenders. By setting aside attitudes toward the two nominees, one avoids contaminating the estimates of partisan support in the electorate. It is possible, for instance, that the gains by the GOP in recent years are tied, in part, to Reagan's personal popularity rather than any enduring change in how the public evaluates the two parties. Thus, by limiting attention to just the public's evaluation of the parties, one can better estimate the underlying support for the parties in the electorate.

To generate these estimates of "underlying support," I first examine shifts in the citizenry's overall evaluation of the parties, and second, and more important, I examine the changes in the public's evaluation of particular issues that make up these broader assessments. Thus, for instance, do citizens view the Democrats or GOP more favorably on such matters as the economy, foreign policy, or race relations? And has the Democratic (or Republican) lead on these issues expanded or contracted over the last ten years?

\section{The Evidence}

To measure change in the public's partisan evaluations, I rely on the National Election Studies' (NES) open-ended questions on the likes/ dislikes of the two parties. The actual wording of these questions is:

- Is there anything in particular you like about the (Democratic or Republican) party? If yes, what is that? Anything else?

- Is there anything in particular you don't like about the (Democratic or Republican) party? If yes, what is that? Anything else?

Scholars have long recognized the merits of these questions. Stokes, 
Campbell, and Miller (1958), for instance, saw two major advantages in using these data. First, since respondents can answer questions in their own words, these questions tap the "diversity or relative frequency of ideas" $(1958,369)$. As a result, one can get a handle on concerns that are salient to the electorate (Kelley 1983; RePass 1971). This aspect of the data may be crucial, since scholars generally agree that an issue must be salient to citizens before it can alter their evaluations of the parties (Campbell et al. 1960; Carmines and Stimson 1981 and 1984; Sundquist 1983). Moreover, since the NES codes up to five comments per respondent for the four questions, one gets a good sense of the diversity of public opinion. ${ }^{1}$ Of course, not all citizens make comments, but respondents, on average, make between three and four observations about the parties.

The second advantage of these data, noted by Stokes, Campbell, and Miller (1958), is that one can examine comparable data from each presidential election since 1952. The data currently span four decades, providing an excellent opportunity to study change in the electorate's partisan evaluations. ${ }^{2}$

\section{Issues}

The comments from the NES open-ended questions can be used to detect the influence of specific "issues" or concerns on the public's evaluation of the parties. The NES codes about 400 different responses. By grouping these comments to represent different political issues, one can estimate their influence on the public's evaluation of parties. The critical question becomes: How does one group these various comments? Stokes, Campbell, and Miller (1958) classified the comments according to the respondents' attitudes toward the candidates, group-related concerns, the parties as managers of government, domestic issues, and matters of foreign policy. Kelley (1983) expanded on work by Stokes and his collaborators, providing a more detailed breakdown of domestic and foreign policy issues. On the domestic front, for instance, he examined such concerns as the "election's economic impact," ideological stance, or medical care.

1. In 1972, the CPS released only three comments per question for each respondent, rather than the normal five. In another version of the data, all five comments were included. I want to thank Michael Kagay for making this latter version available to me. 2. Note that some scholars have serious doubts about the data generated by the like/ dislike questions (see Lodge, McGraw, and Stroh 1989; Smith 1989). Other scholars see merit in these data (Geer 1988 and 1991; Kelley 1983; Knight 1985; RePass 1971; Wattenberg 1990). I prefer to avoid this debate here, and make only the claim that these data shed light on how the electorate judges the parties. 
Building on these earlier works, I developed a coding scheme to examine the following sets of concerns: the economy; foreign policy; race relations; social-welfare matters; political philosophy; concerns about big business and labor; the management of government; and "contemporary" issues, which include references to crime, drugs, busing, abortion, gun control, and women's rights (see the appendix for details about the coding). ${ }^{3}$ These issues, obviously, are only a subset of all possible concerns. But they cover many of the major disputes facing parties and should shed light on how the public evaluates the parties.

\section{Estimating the Influence of Issues}

To determine the impact of an issue on how the electorate evaluates the parties, we must first determine its salience and then estimate whether the public views one party more favorably than the other on that issue. Fortunately, Kelley (1983) provides a way to estimate the salience and the partisan bias of issues using the NES's open-ended questions. According to Kelley, salience is simply the proportion of respondents "who cite a given issue as something to like or dislike about the major parties . . ." $(1983,61) .{ }^{4}$ Bias, on the other hand, is the proportion of citizens who favor one of the parties on a particular issue. To estimate bias, one first subtracts the pro-Republican comments from the pro-Democratic comments for that particular issue. ${ }^{5}$ The result is a scale that can range from +10 , a highly Democratic score, to -10 , a highly Republican score. With this measure, one then divides the number of respondents who favor one party by all respondents who favor either party on that issue, yielding what Kelley calls bias (see Kelley 1983, 60-64).

With measures of salience and bias, one can then calculate the partisan influence of an issue. Here, I want to introduce a new concept,

3. See Kessel 1984 for a different, but useful, coding scheme.

4. One could quarrel with this measure of salience, since for an issue to be salient all an individual has to do is mention it once. Surely, other issues are likely to be important to citizens besides those mentioned in an open-ended format. The problem is that assessing the salience of an issue to the public is difficult. Closed-ended questions do not offer much of an alternative, since they also run into problems (Zaller and Feldman 1990). But, at least, the open-ended format does encourage respondents "to define [their] own issue space by naming issues that were salient to [them]" (RePass 1971, 391).

5. There are two items to keep in mind when one adds and subtracts these comments. First, a "pro-Democratic" comment is either a statement about why a respondent likes the Democratic party or likes the Republican party. The reverse holds for "proRepublican" comments. Second, in the calculation of these scales, I weigh each comment equally. For thoughtful defenses of the equal weighting assumption, see Kagay 1980 and Kelley 1983. 
Net Pull, the relative ability of the two parties to attract supporters on a given issue. To determine the pull of an issue for a party, one multiplies the bias for a party by its salience. The result is the "proportion of ... respondents who see a given issue as favoring a given ... party" (Kelley 1983, 61). One then calculates the pull of any issue for both parties, subtracting the two proportions to yield the Net Pull. The specific formula is:

Net Pull $=($ salience of an issue $\times$ Democratic bias on that issue $)$ - (salience of an issue $\times$ Republican bias on that issue)

Estimates of pull for both parties are necessary, since highly salient issues may have a lot of pull for each party. For example, an issue that is salient to the public with a Democratic bias of $60 \%$ will still help the Republicans gain a more positive evaluation among the $40 \%$ who see the issue favoring the GOP. Therefore, looking only at the pull for one party provides a misleading picture of the overall influence of that issue on the electorate's partisan evaluations. Net Pull avoids this problem by providing direct insight into how an issue yielded change in the net partisan evaluations of the electorate. A useful way to think about this concept is that it estimates the lead one party has over the other on a particular issue.

One final methodological task involves estimating the public's overall evaluation of the two parties. Here I shall follow a simple procedure first adopted by Stokes, Campbell, and Miller (1958): namely, summing all the respondents' likes and dislikes of the two parties. This summation is used to generate three indicators of party support. First, "net Republican score" indicates the proportion of respondents who made more pro-Republican comments than pro-Democratic comments. "Net Democratic score," as one might guess, is just the reverse. "Neutrals," on the other hand, are those citizens who made no comments about either party or who made an equal number of pro-Democratic and pro-Republican comments.

\section{The Findings}

Table 1 reports the public's overall partisan assessments from 1952 to 1988. One obvious pattern in table 1 is that, from 1968 to 1980 , the proportion of neutrals nearly doubled. This trend, which Wattenberg (1990) has carefully documented, suggests that both parties were further away from majority status in the 1980s than they were in the 1950s. My purpose, however, is to examine the shifts in the electorate's relative assessment of the parties, which is well summarized by the net Democratic edge. Here, the results suggest that the GOP has 
Table I. The Electorate's Overall Partisan Evaluations, 1952-88

\begin{tabular}{llllll}
\hline & $\begin{array}{c}\text { Net Democratic } \\
\text { Score }\end{array}$ & $\begin{array}{c}\text { Neutral } \\
\text { Score }\end{array}$ & $\begin{array}{c}\text { Net Republican } \\
\text { Score }\end{array}$ & $\begin{array}{c}\text { Net Democratic } \\
\text { Edge }\end{array}$ & $N$ \\
\hline 1952 & $44.4 \%$ & $16.3 \%$ & $39.3 \%$ & $5.1 \%$ & 1,799 \\
1956 & 44.0 & 22.2 & 33.8 & 10.2 & 1,762 \\
1960 & 44.7 & 21.6 & 33.6 & 11.1 & 1,932 \\
1964 & 48.2 & 25.7 & 26.1 & 22.1 & 1,571 \\
1968 & 37.1 & 23.8 & 39.1 & -2.0 & 1,557 \\
1972 & 35.3 & 35.9 & 28.9 & 6.4 & 1,372 \\
1976 & 38.7 & 37.2 & 24.1 & 14.6 & 2,870 \\
1980 & 33.9 & 41.1 & 25.0 & 8.9 & 1,570 \\
1984 & 34.8 & 38.9 & 26.3 & 8.5 & 2,257 \\
1988 & 36.1 & 34.8 & 29.1 & 7.0 & 2,040 \\
\hline
\end{tabular}

NoTE: The proportions are the result of simply adding up the likes and dislikes of the parties. A net Republican score could range from -1 to -10 . A net Democratic score could fall between 1 and 10 . Individuals who either made no comments or whose comments cancelled each other out were given neutral scores. The net Democratic edge is derived by subtracting the net Republican score from the net Democratic score.

not made significant inroads into Democratic support. If one, for instance, looks at the net Democratic edge between 1952 and 1960, the average lead was about 9 percentage points. From 1980 to 1988 , that lead was about the same -8 percentage points. This is not the only story one could tell, however. If one, instead, compares the net Democratic edge in 1964 to that of 1988, the GOP has made important gains. But it is unclear why the high point of Democratic support should be one's starting point. In contrast, one might compare 1968 to 1988 . In that case, the Democrats have made sizable strides in the last twenty years. Using the low point of Democratic support also poses problems. These results, in sum, are open to a number of interpretations. But it is hard to escape one simple fact: the electorate continues to evaluate the Democrats more positively than the Republicans.

Table 2 provides a detailed breakdown of these evaluations, examining the partisan direction for eight issues across the last four decades. Of all the issues examined, concerns about big business-labor are clearly the most important to the electorate's assessment of parties. From 1952 to 1988 , about $35 \%$ of the electorate, on average, mentioned concerns about labor or big business in their likes and dislikes about the parties. These attitudes have remained decidedly in favor of the Democrats during that time. The Democratic bias has consistently hovered at around $88 \%$, generating net pulls of nearly $30 \%$. No other issue 
Table 2. Changes in the Electorate's Partisan Evaluations, $1952-88$ (in percentages)

\begin{tabular}{|c|c|c|c|c|c|c|c|c|c|c|}
\hline Issue & 1952 & 1956 & 1960 & 1964 & 1968 & 1972 & 1976 & 1980 & 1984 & 1988 \\
\hline \multicolumn{11}{|c|}{ Government management } \\
\hline Salience & 25 & 9 & 11 & 14 & 15 & 10 & 14 & 14 & 12 & 19 \\
\hline Dem bias & 7 & 18 & 34 & 42 & 29 & 45 & 34 & 19 & 33 & 36 \\
\hline Net pull & -22 & -6 & -4 & -2 & -6 & -1 & -5 & -9 & -5 & -6 \\
\hline \multicolumn{11}{|c|}{ Foreign policy } \\
\hline Salience & 29 & 24 & 25 & 17 & 25 & 18 & 14 & 12 & 21 & 25 \\
\hline Dem bias & 18 & 18 & 33 & 37 & 15 & 32 & 31 & 25 & 44 & 39 \\
\hline Net pull & -18 & -15 & -8 & -4 & -18 & -7 & -4 & -6 & -3 & -6 \\
\hline \multicolumn{11}{|l|}{ Race } \\
\hline Salience & 5 & 6 & 8 & 15 & 9 & 3 & 3 & 3 & 2 & 2 \\
\hline Dem bias & 63 & 60 & 72 & 54 & 68 & 70 & 80 & 98 & 82 & 61 \\
\hline Net pull & 1 & 1 & 4 & 1 & 3 & 1 & 2 & 3 & 2 & 1 \\
\hline \multicolumn{11}{|c|}{ The economy } \\
\hline Salience & 60 & 32 & 34 & 21 & 30 & 20 & 26 & 19 & 24 & 31 \\
\hline Dem bias & 56 & 62 & 54 & 58 & 41 & 64 & 66 & 37 & 46 & 39 \\
\hline Net pull & 7 & 8 & 3 & 4 & -5 & 6 & 9 & -5 & -2 & -9 \\
\hline \multicolumn{11}{|c|}{ Big business-labor } \\
\hline Salience & 39 & 41 & 37 & 36 & 32 & 35 & 34 & 34 & 31 & 35 \\
\hline Dem bias & 88 & 88 & 85 & 87 & 87 & 89 & 88 & 88 & 89 & 88 \\
\hline Net pull & 30 & 31 & 36 & 26 & 24 & 27 & 26 & 25 & 24 & 27 \\
\hline \multicolumn{11}{|l|}{ Philosophy } \\
\hline Salience & 23 & 15 & 19 & 23 & 25 & 18 & 19 & 20 & 24 & 26 \\
\hline Dem bias & 42 & 45 & 40 & 28 & 32 & 33 & 32 & 36 & 36 & 41 \\
\hline Net pull & -4 & -2 & -4 & -11 & -9 & -6 & -7 & -5 & -7 & -5 \\
\hline \multicolumn{11}{|c|}{ Social welfare } \\
\hline Salience & 17 & 18 & 17 & 17 & 16 & 12 & 11 & 12 & 15 & 23 \\
\hline Dem bias & 86 & 81 & 70 & 77 & 64 & 47 & 50 & 42 & 57 & 69 \\
\hline Net pull & 12 & 11 & 7 & 9 & 5 & -1 & 0 & -2 & 2 & 9 \\
\hline \multicolumn{11}{|c|}{ "Contemporary" issues } \\
\hline Salience & - & - & - & - & - & 4 & 3 & 2 & 6 & 8 \\
\hline Dem bias & - & - & - & - & - & 44 & 36 & 57 & 44 & 34 \\
\hline Net pull & - & - & - & - & - & -1 & -1 & 1 & -1 & -3 \\
\hline
\end{tabular}

NoTE: Salience is the proportion of respondents who made at least one comment about the issue. Dem bias is the proportion of respondents who see an issue favoring the Democrats. The Republican bias equals $100 \%$ minus the Democratic bias. Neutrals are excluded from this calculation. Net pull is the proportion of respondents "pulled" by the issue toward a particular party. A negative sign means the pull is toward the Republican party. Pull is arrived at by multiplying salience by bias for the party.

studied here has had such a powerful effect on the public's assessment of the parties. Interestingly, one foundation of the New Deal was that the Democrats were the party of the working man and woman, and that image appears to remain a centerpiece of the citizens' partisan evaluations-even 50 years after FDR set the New Deal in motion.

While the Democrats benefit greatly from that issue, other concerns 
have consistently favored the GOP. For instance, comments about foreign policy, political philosophy, and how the government is run have all exhibited a pro-Republican edge in each of the last ten presidential elections. The degree of support for the GOP varies from election to election, but the net pulls show a consistent GOP advantage. While the Republicans have positive ratings on these three issues, their lead has not increased in recent years. If one compares, for instance, the net pulls for these three issues in 1988 to the same measures in 1980 (or 1976), there is very little change.

The influence of concerns about social welfare, on the other hand, sends mixed signals. From 1972 to 1980, the GOP experienced sizable gains in the public's evaluation on this issue. During these three elections, the Democratic bias averaged about $46 \%$. This shift was quite a reversal of fortunes: between 1952 and 1964 the Democratic bias was about $79 \%$. But in the last two elections, the Democrats have reestablished an edge on these matters. In 1988, for instance, the net pull for the Democrats was about the same as it was in 1960 and 1964. According to these data, there does not appear to be a rejection of the Democrats' position on social-welfare concerns by the public in 1984 or 1988-one of the commonly cited cornerstones of an emerging Republican majority.

One potentially important change in favor of the GOP does, however, emerge on the economic front. Since 1980, the public has begun to view the GOP more favorably on matters pertaining to the economy. In 1976, for instance, the Democratic bias was 66\%. By 1988, it had slipped to $39 \%$, yielding a net pull of $9 \%$ for the Republicans. It appears that Carter's economic difficulties combined with Reagan's economic successes have led the public to think of the Republicans as the "party of prosperity." And since economic issues are often salient when citizens evaluate the parties, this change bodes well for the GOP.

The two remaining concerns, "contemporary" and racial issues, have simply not been salient enough to generate significant change in the public's evaluation of the parties. The low salience of "contemporary" issues has led to net pulls of just $-1 \%$ in three of the last five elections. Racial issues follow a similar pattern. Between 1972 and 1988 , only about $2 \%$ to $3 \%$ of the electorate made any references to racial concerns. With such low salience, these issues have been unable to recast the electorate's partisan evaluations. The only exception was 1964 , when racial matters were salient to $15 \%$ of the public. But in that year the Democratic bias was just $54 \%$, leading to a small overall impact for those concerns. ${ }^{6}$

6. One may find this last set of findings surprising, given that race is generally viewed as a central issue in U.S. politics over the last 40 years (see Carmines and Stimson 


\section{The Newest Cohort}

Even though tables 1 and 2 indicate that the Democrats continue to garner more favorable evaluations than the Republicans, perhaps the youngest members of the electorate have developed more positive evaluations of the GOP than of the Democrats. Because of generational replacement, these changes among the youth could fuel a future GOP majority, as Norpoth (1987) and Norpoth and Kagay (1989) suggest. To test this possibility, I examined the partisan evaluations of the 18-29-year-olds for the last three presidential elections.

The data in table 3, however, lend little support to the interpretation that the GOP has built a favorable impression among the youth of the 1980s. In each of the last three presidential elections, these citizens have favored the Democratic party. The Democratic edge ranged from 2 percentage points in 1980 to 12 percentage points in 1984. These young citizens do, however, tend to be more neutral in their assessment of parties than the entire public, suggesting that neither party has captured their imaginations. But even though these 18-29-year-olds have less to say about the parties, the partisan content of their responses is similar to that of the entire electorate (see table 4). Comments about labor and big business, for example, strongly favor the Democrats. For social welfare concerns, the Democrats maintained a small edge in net pull in 1984 and 1988, again indicating that, among these newest voters, there has not been a widespread rejection of the Democrats' position on social spending. On economic issues, the GOP holds a lead comparable to its lead among the entire electorate. All in all, it would be difficult to argue that the newest members of the electorate will provide a foothold for the GOP as it strives to become the majority party.

\section{Conclusion}

These results show that the Democratic party, despite recent defeats in presidential elections, remains the favored party. The Democratic edge in the public's overall partisan evaluations is about the same in

\footnotetext{
1989). These data may underestimate the influence of racial issues, especially since respondents may be hesitant to mention these concerns for fear of saying something socially unacceptable. This argument surely has merit, but there may be more to the story. In 1964, for instance, the salience of racial concerns rose to $15 \%$, suggesting that a good number of citizens were willing to mention this matter in some situations. In addition, the proportion of citizens citing racial concerns has dropped since 1964, suggesting that racial issues are less salient to the public's partisan evaluations in the $1980 \mathrm{~s}$ than they were in the 1960s.
} 
Table 3. Changes in Partisan Evaluations of 18-29-Year-Olds, $1980-88$ (in percentages)

\begin{tabular}{lccccc}
\hline & $\begin{array}{c}\text { Net Democratic } \\
\text { Score }\end{array}$ & $\begin{array}{c}\text { Neutral } \\
\text { Score }\end{array}$ & $\begin{array}{c}\text { Net Republican } \\
\text { Score }\end{array}$ & $\begin{array}{c}\text { Net Democratic } \\
\text { Edge }\end{array}$ & $N$ \\
\hline 1980 & 25 & 52 & 23 & 2 & 422 \\
1984 & 33 & 46 & 21 & 12 & 548 \\
1988 & 29 & 46 & 25 & 4 & 450 \\
\hline
\end{tabular}

Note: See table 1 for description of measures.

the 1980 s as it was in the 1950s. In addition, the electorate's relative evaluation of the Democrats and Republicans on seven of the eight issues studied here have not changed greatly over the last 20 years. The Democrats continue to benefit greatly from concerns associated with big business and labor and also remain ahead on social-welfare matters. The only significant change occurs for economic issues, where the GOP have built a lead over the Democrats in recent years. Finally, the youth of the nation do not appear to be pro-Republican in their evaluations of the parties, suggesting that generational change may not lead to a GOP majority. These data, in sum, suggest that continuity, rather than change, is an important theme underlying the public's relative evaluations of the parties from 1952 to 1988.

This analysis also has more general lessons for the study of partisan change. Specifically, the idea that issues pull and tug on citizens' overall evaluations of parties highlight the many obstacles that face the minority party's climb to the top. First, table 2 shows that few issues have had great impact on the overall partisan evaluations of the electorate. Except for concerns about big business and labor, no issue has had an average net pull of more than $10 \%$ during the 36-year period. It makes sense that most issues will be salient to only a portion of the population, especially given the diversity of the U.S. electorate. But because of this diversity, most issues simply lack the power to reshape the partisan moorings of the entire electorate.

A second obstacle is that many issues confront the public at any one time-each tugging and pulling on the citizens' overall evaluations of the parties. The economic growth during the Reagan administration, for instance, has surely given many young voters reason to support the Republicans. But simultaneously, other positions of the GOP, such as those on social-welfare issues, may be retarding partisan change toward them. Since there is this pull-and-tug effect and few issues have widespread salience, it becomes clearer why it has been over 50 years 
Table 4. Changes in Partisan Issue Evaluations of 18-29-Year-Olds, 1980-88 (in percentages)

\begin{tabular}{|c|c|c|c|}
\hline Issue & 1980 & 1984 & 1988 \\
\hline \multicolumn{4}{|c|}{ Government management } \\
\hline Salience & 12 & 10 & 14 \\
\hline Dem bias & 19 & 43 & 40 \\
\hline Net pull & -7 & -1 & -3 \\
\hline \multicolumn{4}{|c|}{ Foreign policy } \\
\hline Salience & 13 & 24 & 27 \\
\hline Dem bias & 27 & 53 & 36 \\
\hline Net pull & -6 & 1 & -8 \\
\hline \multicolumn{4}{|l|}{ Race } \\
\hline Salience & 2 & 2 & 1 \\
\hline Dem bias & 100 & 89 & 83 \\
\hline Net pull & 2 & 2 & 1 \\
\hline \multicolumn{4}{|c|}{ The economy } \\
\hline Salience & 17 & 20 & 28 \\
\hline Dem bias & 14 & 42 & 35 \\
\hline Net pull & -12 & -3 & -8 \\
\hline \multicolumn{4}{|c|}{ Big business-labor } \\
\hline Salience & 20 & 24 & 24 \\
\hline Dem bias & 84 & 87 & 86 \\
\hline Net pull & 14 & 18 & 17 \\
\hline \multicolumn{4}{|c|}{ Social welfare } \\
\hline Salience & 8 & 11 & 16 \\
\hline Dem bias & 39 & 73 & 78 \\
\hline Net pull & -2 & 5 & 9 \\
\hline \multicolumn{4}{|l|}{ Philosophy } \\
\hline Salience & 17 & 20 & 20 \\
\hline Dem bias & 46 & 54 & 57 \\
\hline Net pull & -1 & 2 & 3 \\
\hline \multicolumn{4}{|c|}{ "Contemporary" issues } \\
\hline Salience & 2 & 7 & 7 \\
\hline Dem bias & 40 & 32 & 50 \\
\hline Net pull & -1 & -3 & 0 \\
\hline
\end{tabular}

Note: See table 2 for description of measures. 
since a new majority party emerged. The forces associated with lowsalience issues can only chip away at the partisan evaluations of the electorate.

This argument strongly suggests that permanent, large-scale shifts in the overall partisan evaluations of the public may be impossible without both a highly salient issue that dominates the concerns of most citizens and an issue that is perceived by the public as heavily favoring one party_ just as Sundquist (1983) and others have argued. The Great Depression and FDR's response to it apparently brought such a shift. Without a shock of similar magnitude, partisan evaluations will change only slowly and modestly, as Key (1959) observed over 30 years ago. Given the logic of this analysis, the pro-Democratic evaluations may well continue. And at least at this point, Reagan's legacy, although important, does not appear to be strong enough to have significantly altered the overall partisan evaluations of the U.S. public, suggesting that the Democrats have reason for optimism as they enter the decade of the 1990s.

\section{Appendix 1}

Open-ended comments are recoded into eight different groups of issues. A list of the specific codes for each issue and a sample of some of the kinds of comments in the categories is given below. For a detailed account of Kelley's coding scheme for the 1964 and 1972 elections, see Kelley 1983 (239-62). No measure of coding reliability is available, since only a single coder (the author) was used.

I have only presented the coding scheme for 1984 . From 1972 to 1988 , the NES's coding arrangement has been nearly identical. Prior to 1972, however, the codes varied a bit from year to year. The actual content of the responses did not change, but the numeric code assigned to the responses did shift. Exact codes for the years before 1972 can be obtained by writing to the author.

The Economy: 605, 606, 901, 926 to 941,1007 to 1009

- The party would spend less/more

- The party would lower/raise taxes

- The party supports a government program to create jobs

- Inflation would be better/worse under the party

Social-Welfare Policies: 905-15, 920-25, 942-54, 1001, 1003, 1215-16, 1219-22

- The party favors welfare/poverty programs

- The party favors expansion of social security/pensions

- The party is against aid to education

- The party is against national health insurance

Government Management: 601-4, 607-20, 697

- The party runs a good/efficient administration

- The party runs honest government 
- The party supports reforming the bureaucracy

- The party works well with Congress

Foreign Policy: 1101-97

- The party favors a strong military

- The party handles trouble spots well

- The party handles Russia well

- The party favors a nuclear freeze

Big Business-Labor: 952-58, 1201, 1202, 1205-10, 1233, 1234

- The party favors privileged people

- The party supports the common man/working people

- The party supports unions

- The party helps the poor

Race: 946-48, 1217-18

- The party favors civil rights

- The party is opposed to integration

- The party supports voting rights

- The party favors blacks

Political Philosophy: 162-65, 805-28, 833-34, 837-38, 902, 904

- The party is against social change

- The party favors the work ethic

- The party is opposed to a planned economy

- The party is too liberal

Contemporary Issues: 968-86, 988-96, 1223-26

- The party supports law and order

- The party is too permissive

- The party favors a woman's right to an abortion

- The party is opposed to gun control

\section{References}

Campbell, Angus, Philip E. Converse, Warren E. Miller, and Donald E. Stokes. 1960. The American Voter. New York: Wiley.

Carmines, Edward G., and James A. Stimson. 1981. "Issue Evolution, Population Replacement and Normal Partisan Change." American Political Science Review 75:107-18.

Carmines, Edward G., and James A. Stimson. 1984. "The Dynamics of Issue Evolution: The Unitcd States." In Electoral Change in Advanced Industrial Democracies, ed. Russell Dalton, Scott Flanigan, and Paul Allen Beck, 134-58. Princeton: Princeton University Press.

Carmines, Edward G., and James A. Stimson. 1989. Issue Evolution. Princeton: Princeton University Press.

Cavanagh, Thomas, and James Sundquist. 1985. "The New Two-Party System." In The New Direction of American Politics, ed. John E. Chubb and Paul E. Peterson, 33-68. Washington, DC: Brookings Institution.

Geer, John G. 1988. "What Do Open-ended Questions Measure?' Public Opinion Quarterly 52:365-71.

Geer, John G. 1991. “Do Open-ended Questions Measure 'Salient' Issues?” Public Opinion Quarterly. In press.

Kagay, Michael. 1980. "On Two Models of Voter Decision Making: Stokes's Six Components and the Kelley-Mirer Rule." Princeton University. Photocopy. 
Kelley, Stanley, Jr. 1983. Interpreting Elections. Princeton: Princeton University Press.

Kessel, John H. 1984. Presidential Parties. Homewood, IL: Dorsey Press.

Key, V. O. 1959. "Secular Realignment and the Party System." Journal of Politics 21:198-210.

Knight, Kathleen. 1985. "Ideology in the 1980 Election: Ideological Sophistication Does Matter." Journal of Politics 47:828-53.

Lodge, Milton, Kathleen M. McGraw, and Patrick Stroh. 1989. "An Impression-driven Model of Candidate Evaluation." American Political Science Review 83:399-420.

Norpoth, Helmut. 1987. "Under Way and Here to Stay: Party Realignment in the 1980s?" Public Opinion Quarterly 51:376-91.

Norpoth, Helmut, and Michael Kagay. 1989. "Another Eight Years of Republican Rule and Still No Partisan Realignment?" Paper presented at the annual meeting of the American Political Science Association, Atlanta, GA.

Petrocik, John R. 1987. "Realignment: The South, New Party Coalitions, and the Election of 1984 and 1986." In Where's The Party? 21:33-59. Washington, DC: Center for National Policy.

RePass, David E. 1971. "Issue Salience and Party Choice." American Political Science Review 65:389-400.

Shanks, Merrill J., and Warren E. Miller. 1989. "Alternative Interpretations of the 1988 Election." Paper presented at the annual meeting of the American Political Science Association, Atlanta, GA.

Smith, Eric R. A. N. 1989. The Unchanging American Voter. Berkeley: University of California Press.

Stokes, Donald, Angus Campbell, and Warren E. Miller. 1958. "Components of Electoral Decision." American Political Science Review 52:367-87.

Sundquist, James L. 1983. Dynamics of the Party System. Washington, DC: Brookings Institution.

Wattenberg, Martin P. 1987. "The Hollow Realignment: Partisan Change in a Candidate-centered Era." Public Opinion Quarterly 51:58-74.

Wattenberg, Martin P. 1990. The Decline of American Political Parties. 3d ed. Cambridge, MA: Harvard University Press.

Zaller, John, and Stanley Feldman. 1990. "Answering Questions vs. Revealing Preferences: A Simple Theory of the Survey Response." Paper presented at the annual meeting of the Political Methodology Society. 